\title{
Nicotine alters progesterone and estradiol levels during the first trimester of pregnancy in Wistar rats
}

\author{
Damilare H Adeyemi ${ }^{1,2}$, Ibukun P Oyeyipo ${ }^{1}$, Kikelomo A Akanbi ${ }^{1}$, Tolulope Oluwole ${ }^{2}$ \\ ${ }^{1}$ Department of Physiology, College of Health Sciences, Osun State University, Osogbo, Nigeria \\ ${ }^{2}$ Department of Physiology, College of Medicine, University of Ibadan, Ibadan, Nigeria
}

\begin{abstract}
Objective: This study was designed to investigate the effect of nicotine on serum progesterone and estradiol levels as possible cause of abortion during first trimester of gestation in female Wistar rats.

Methods: Fourteen female rats with regular estrous cycles in the same phase of cycle were divided into two groups (Control and Nicotine-treated) with each group receiving $1 \mathrm{ml}$ of distilled water and $1 \mathrm{mg} / \mathrm{kg}$ of nicotine respectively for the first seven days of pregnancy (GD17 ). The animals were sacrificed on the $8^{\text {th }}$ day and blood samples were collected for hormonal analyses. Ovaries and uteruses were excised, weighed, and prepared for histological study.

Results: This study revealed a significant decrease in serum progesterone and estradiol levels in the nicotine-treated group when compared to controls. The histological findings equally showed degeneration in the cytoarchitecture of the ovary of the nicotine-treated group.

Conclusion: The observed hormonal imbalances and alteration in the cytoarchitecture of the ovary caused by nicotine in the first trimester of pregnancy may result in abortion during this period.
\end{abstract}

Keywords: nicotine, maternal, abortion, uterus, ovary, pregnancy

\section{INTRODUCTION}

Numerous epidemiological studies have revealed that tobacco is the most commonly used drug during pregnancy and despite the knowledge of its deleterious effects on various body systems, this habit still remains a public health concern worldwide. This could perhaps be due to the fact that not only active smokers but also passive smokers are exposed to tobacco consumption and inhalation in society. The highest prevalence of smoking is observed in people of childbearing age, with $46 \%$ of smokers aged between 20 and 39 years (Langgassner, 1999). Cigarette smoking during pregnancy adversely affects pre and postnatal growth and increases the risk of fetal mortality (Kleinman et al., 1988), cognitive development (Jacobsen et al., 2007), and morbidity (Habek et al., 2002). Other several negative effects associated with maternal prenatal smok ing include preterm delivery, placental abruption, sudden infant death syndrome (SIDS), congenital anomalies, ectopic pregnancy, preeclampsia risk and poor neuropsychological performance (Buhimschi et al., 1996; Thakur et al., 2013). Maternal pre natal smoking has also been associated with stillbirth and spontaneous abortion (Omotoso et al., 2013).

Nicotine is considered the main chemical found in tobacco and cigarette smoke and it remains the entity responsible for its engendering use and dependence (Oyeyipo et al., 2010). It can be consumed in different form such as smokeless tobacco products like snuff and chewing tobacco. Numerous previous studies have shown that nicotine is responsible for the deleterious physiological effects associated with smoking (Tuormaa, 1995; Oyeyipo et al.,
2011). It has also been reported that nicotine consumption confers serious harmful effect on visceral tissues in women (Rosevear et al., 1992). The effects of nicotine administration on weight and histology of some vital visceral organs in female albino rats have also been documented (Iranloye \& Bolarinwa, 2009). Repeatedly, epidemiologic studies have indicated that women who smoke heavily and regularly may suffer spontaneous abortions during the first trimester of pregnancy (Lambers \& Clark, 1996; Omotoso et al., 2013).

The literature has shown that hormonal concentrations during pregnancy predict maternal competence in preventing pregnancy loss and still birth (Xue et al., 2010). In normal pregnant females, tremendous quantities of estrogen and progesterone are secreted by the placenta alongside the ovaries. It has been documented that plasma progesterone levels increase in early pregnancy, decrease in mid-pregnancy, and increase again in the last weeks before parturition (Walsh et al., 1979). Therefore, alterations in this sequence will consequently affects pregnancy.

Although it has been reported that exposure to nicotine during the first trimester of pregnancy causes abortion, it is still unclear how nicotine causes abortion during this period. Furthermore, several studies have also established that the effects of any pharmacological agent depend not solely on the dose administered, but also on the time of administration in relation to embryogenesis. Therefore, this study was undertaken to investigate the effect of nicotine on serum progesterone and estradiol levels as a possible cause of abortion during the first trimester of gestation in female Wistar rats.

\section{MATERIALS AND METHODS \\ Drug}

Nicotine hydrogen tartrate was purchased from Sigma Aldrich, South Africa. The nicotine dosage freshly prepared in normal saline was administered orally at $1 \mathrm{mg} / \mathrm{kg}$ body weight. The stock solutions were stored in foil-wrapped glass bottles at $4^{\circ} \mathrm{C}$ throughout the seven days of the experiment.

\section{Experimental design}

This study was carried out in accordance with the guidelines of the U.S. National Institute of Health (NIH) care on use of animals in research and teaching (NIH, 1996). Adult female Wistar rats weighing between 150$200 \mathrm{~g}$ were purchased from the main animal house, College of Health Sciences, LAUTECH, Osogbo, and housed at the central animal house of Osun State University, Osogbo. The animals were allowed to acclimatize for two weeks prior to the commencement of the study. The animals were fed with pelletized rat chow and clean water ad libitum. Animals were also maintained in a well-ventilated room and kept on a $12 \mathrm{~h}$ day/night cycle. Fourteen pregnant rats were randomly divided into two groups of seven rats each and treated orally for 7 days as follows: Group 1 rats received $1 \mathrm{ml}$ of distilled water and served as controls, while Group 2 rats received $1 \mathrm{mg} / \mathrm{kg}$ body weight of nicotine and served as the treatment group. The dosage used was obtained from a previous study that administered to mimic 
what is obtained when 20 cigarette sticks are smoked daily (Oyeyipo et al., 2010).

\section{Animals mating and pregnancy detection}

The reproductive cycle of each adult female Wistar rats was monitored by vaginal smear method to establish when mating should occur. Female Wistar rats were introduced to their male counterparts at the onset of the estrous phase. Pregnancy was confirmed through vaginal smears in the early hours of the following morning after perceived mating, as indicated by the presence of mucous plug and sperm cells in the vaginal smear viewed with the aid of a microscope. The day on which spermatozoa were found in vaginal lavage was marked as gestation day 1 (GD 1).

\section{Sacrifice and specimen collection}

On the $8^{\text {th }}$ day of pregnancy, animals were anaesthetized and dissected. Blood was collected from each animal through cardiac puncture into both plain serum for determination of estrogen and progesterone. Ovaries and uteruses were harvested and weighed before fixation in Bouin's fluid for histological studies. The blood sample was spun at 3,000 rpm for five minutes. Serum estrogen and progesterone levels were then determined.

\section{Hormonal assay}

An enzyme-based immunoassay system was used to measure progesterone and estrogen levels in the obtained serum samples. The EIA kit was procured from Immunometrics (London, UK) and contained the respective EIA enzyme label, EIA substrate reagent, and EIA quality control sample. Quality control was carried out at the beginning and at the end of the assay to ascertain the acceptability with respect to bias and batch variation.

\section{Histological studies}

The ovaries were dyed with Hematoxylin and Eosin stains. Organs were fixed in Bouin's fluid for a few hours before they were transferred into $10 \%$ formalin for histological evaluation. The tissues were routinely processed, examined, and viewed under the light microscope. Photomicrograph of the slide was then taken.

\section{Statistical analysis}

Data obtained are presented as mean \pm S.E.M for each group. The test of significance between two groups was estimated by Student's t-test. $p<0.05$ was considered significant.

\section{RESULTS}

Effect of nicotine on body weight, visceral and reproductive organs weight

The result showed that there was a significant difference in the body weight of the nicotine-treated group compared to controls (Table 1). Ovarian weight was also increased in the nicotine-treated group when compared to the control group (Table 2). However, there was no significant difference in the uterine weight of the nicotine-treated group compared to controls (Table 2). The livers, lungs and spleens of the nicotine-treated animals were significantly decreased $(p<0.05)$, while the weight of hearts and kidneys in the two groups were comparable, as shown in Table 3.

Effects of nicotine on serum estrogen and progesterone concentration

Serum concentrations of estrogen and progesterone were significantly decreased in the nicotine-treated group when compared to the control group (Figure 1).
Table 1. Effects of nicotine treatment on body weight in pregnant rats

\begin{tabular}{|l|c|c|}
\hline Treatment & $\begin{array}{c}\text { Initial weight } \\
(\mathbf{g})\end{array}$ & $\begin{array}{c}\text { Final weight } \\
(\mathbf{g})\end{array}$ \\
\hline Control & $196 \pm 8.86$ & $213 \pm 8.89$ \\
\hline Nicotine & $199 \pm 11.45$ & $190 \pm 11.51 *$ \\
\hline
\end{tabular}

Values are mean \pm SEM, $n=7$,

$p<0.05$ indicates significant difference from control

Table 2. Effects of nicotine treatment on reproductive organs weight in female Wistar rats

\begin{tabular}{|l|c|c|}
\hline Treatment & $\begin{array}{c}\text { Uterine weight } \\
(\mathbf{g})\end{array}$ & $\begin{array}{c}\text { Ovarian weight } \\
(\mathbf{g})\end{array}$ \\
\hline Control & $1.32 \pm 0.36$ & $0.88 \pm 0.05$ \\
\hline Nicotine & $1.10 \pm 0.19$ & $1.10 \pm 0.19 *$ \\
\hline
\end{tabular}

Values are mean \pm SEM, $n=7$,

$p<0.05$ indicates significant difference from control

Table 3. Effects of nicotine treatment on visceral organs weight in female Wistar rats

\begin{tabular}{|l|c|c|c|c|c|}
\hline $\begin{array}{l}\text { Treat- } \\
\text { ment }\end{array}$ & $\begin{array}{c}\text { Liver } \\
(\mathbf{g})\end{array}$ & $\begin{array}{c}\text { Lungs } \\
(\mathbf{g})\end{array}$ & $\begin{array}{c}\text { Kidney } \\
(\mathbf{g})\end{array}$ & $\begin{array}{c}\text { Spleen } \\
(\mathbf{g})\end{array}$ & $\begin{array}{c}\text { Heart } \\
(\mathbf{g})\end{array}$ \\
\hline Control & $\begin{array}{c}7.78 \pm \\
0.74\end{array}$ & $\begin{array}{c}1.72 \pm \\
0.08\end{array}$ & $\begin{array}{c}0.64 \pm \\
0.75\end{array}$ & $\begin{array}{c}0.84 \pm \\
0.13\end{array}$ & $\begin{array}{c}0.92 \\
\pm \\
0.08\end{array}$ \\
\hline \multirow{3}{*}{ Treated } & $4.10 \pm$ & $1.44 \pm$ & $1.10 \pm$ & $0.56 \pm$ & $\begin{array}{c}1.44 \\
\pm \\
\end{array}$ \\
& $0.19 *$ & $0.04 *$ & 0.19 & $0.75^{*}$ & 0.04 \\
\hline
\end{tabular}

Values are mean \pm SEM, $\mathrm{n}=7$,

$p<0.05$ indicates significant difference from control

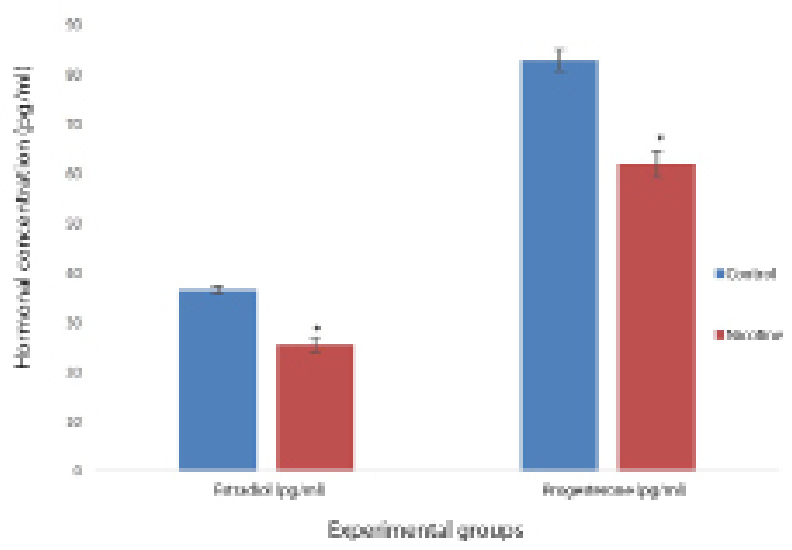

Figure 1. Effects of nicotine on serum estrogen and progesterone levels in female Wistar rats. Values are mean $\pm \mathrm{SEM}, \mathrm{n}=7, * p<0.05$ indicates significant difference from control

Effects of nicotine on histology of the ovary

Photomicrographs of the ovary sections of control animals stained with Hematoxylin and Eosin revealed normal ovarian stroma. There were some follicles with normal differential stages of maturation consisting majorly 
of graffian follicles, normal theca cells and no vascular congestion, while the photomicrographs of the nicotine treatment group showed normal ovarian stroma with luteinization within granular cells. There was severe vascular congestion and the stroma showed mild infiltration of inflammatory cells as seen in Figure 2 .
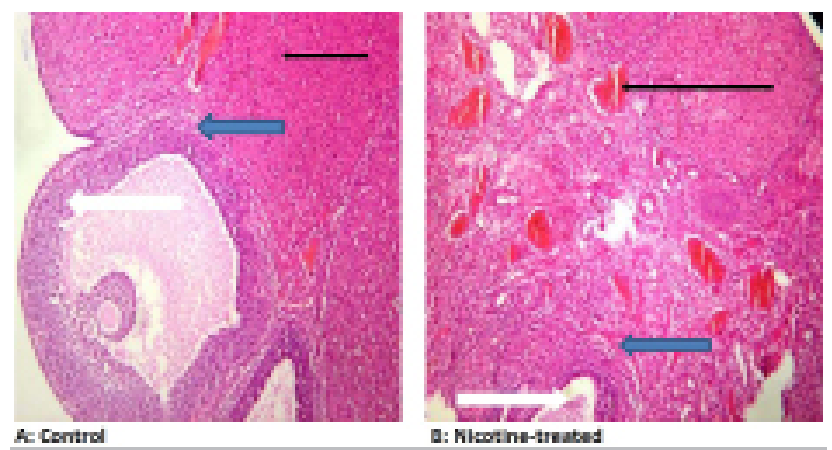

Figure 2. Effects of nicotine on ovarian histology in pregnant Wistar rats. Mag: X400. H\&E Staining technique A: Photomicrograph of an ovary section of control group stained with Haematoxylin and Eosin showing normal ovarian stroma (Slender arrow). There are some follicles with normal differential stages of maturation consisting majorly of graffian follicles (White arrow). There are normal theca cells (Blue arrow) seen and no vascular congestion B: Photomicrograph of an ovary section of nicotine treatment group stained with Haematoxylin and Eosin showing normal ovarian stroma with luteinization within the granular cells. There are some follicles with differential stages of maturation consisting of premordial and antral follicles (white arrow). There are normal theca cells (blue arrow) seen. There are severe vascular congestion seen and the stroma shows mild infiltration of inflammatory cells (Slender arrow)

\section{DISCUSSION}

The aim of the present study was to investigate the effects of nicotine on maternal serum progesterone and estradiol concentrations during the first trimester of pregnancy in Wistar rats. It has been observed that humans are exposed to nicotine during this period of development either directly (active smoking) or indirectly (passive smoking). From literature, a number of studies have established that the effects of any pharmacological agent depend not solely on the dose administered, but also on the time of administration in relation to embryogenesis. Reports from numerous studies have suggested that heavy consumption of nicotine during the first trimester of pregnancy causes abortion (Underwood et al., 1965; Omotoso et al., 2013). There was a significant reduction in the mean body weight of the nicotine-treated animals compared to controls, while there was a significant increase in the mean ovarian weight of the nicotine-treated animals compared to controls.

The observed weight loss in the nicotine-treated group may have resulted from loss of appetite attributed to nicotine intake. This is in agreement with previous literature that revealed the effects of nicotine on the satiety center in the hypothalamus and subsequent decreases in food intake (Ramos et al., 2004; Chen et al., 2012). It is well known that smoking alters feeding patterns by reducing food intake, consequently lowering body weight (Jo et al., 2002). The ability of nicotine to regulate appetite and body weight is often cited as the primary reason for smoking initiation in young people, especially teenage girls (Zoli \& Picciotto,
2012). The weight loss observed in the nicotine-treated group may also have resulted from increased energy expenditure exerted by nicotine (Omotoso et al., 2013).

Maternal smoking has been a known cause of intrauterine growth restriction, and pregnant women who smoke are susceptible to increased risks of preterm labor, premature rupture of membranes, and premature delivery (Narahara \& Johnston, 1993). Nicotine is considered to be teratogenic and might cause the following during pregnancy: increased risk of spontaneous abortion among smokers (Omotoso et al., 2013); delayed implantation of blastocyst (Card \& Mitchell, 1979); and delayed embryonic maturation (Benowitz, 1996). It has been documented that hormonal concentrations during pregnancy predict maternal competence in preventing pregnancy loss and stillbirth (Xue et al., 2010), and that increased progesterone levels are necessary for endometrial preparation of the uterus for blastocyst implantation and to decrease the frequency and intensity of uterine contractions, thereby helping to prevent the expulsion of the already implanted ovum. However, results obtained in this study revealed a sharp decline in the estrogen and progesterone levels of the rats treated with nicotine during this gestation period (GD1-7).

Furthermore, it has been well documented that plasma progesterone and estradiol levels increase in early pregnancy (Walsh et al., 1979). However, findings from this study revealed that progesterone and estrogen levels reduced drastically in the nicotine-treated animals as compared with controls. The observed reduction in both estrogen and progesterone levels in this study might be seen as a result of direct effect on reproductive organs. This was corroborated by findings from histology that showed that the pathologies observed in the ovarian histology of the nicotine-treated group might be regarded as severe when compared to control animals. Some of the areas of the degenerating ovary had severe vascular congestion and the stroma showed mild infiltration of inflammatory cells; this alteration in this structure might interfere with normal ovarian function. In consonance, Iranloye \& Bolarinwa (2009) revealed that nicotine exerts antifertility effects on female albino rats by disrupting the cytoarchitecture of some reproductive organs.

In conclusion, this study suggested that the observed hormonal imbalances and distortion of ovarian cytoarchitecture might cause spontaneous abortion in the first trimester of pregnancy. Exposure to nicotine at this critical period of gestation also altered some reproductive hormones necessary for the maintenance of pregnancy, in Wistar rats. This might be attributable to its potential effects on the hypothalamus, which consequently altered the hypothalamic-pituitary-gonadal axis. Further studies are therefore required to explore possible mechanism(s) responsible for hormonal imbalances during this period.

\section{CONFLICT OF INTERESTS}

None declared.

\section{Corresponding author:}

Ibukun P Oyeyipo

Department of Physiology, College of Health Sciences, Osun State University, Osun State - Nigeria

E-mail:greatibuks@yahoo.com

\section{REFERENCES}

Benowitz NL. Pharmacology of nicotine: addiction and therapeutics. Annu Rev Pharmacol Toxicol. 1996;36:597-613. PMID: 8725403 DOI: 10.1146/annurev.pa.36.040196.003121 
Buhimschi I, Ali M, Jain V, Chwalisz K, Garfield RE. Differential regulation of nitric oxide in the rat uterus and cervix during pregnancy and labour. Hum Reprod. 1996;11:1755-66. PMID: 8921128 DOI: 10.1093/oxfordjournals.humrep.a019481

Card JP, Mitchell JA. The effects of nicotine on implantation in the rat. Biol Reprod. 1979;20:532-9. PMID: 454752 DOI: $10.1095 /$ biolreprod20.3.532

Chen $\mathrm{H}$, Saad S, Sandow SL, Bertrand PP. Cigarette smoking and brain regulation of energy homeostasis. Front Pharmacol. 2012;3:147. PMID: 22848202 DOI: 10.3389/fphar.2012.00147

Habek D, Habek JC, Ivanisević M, Djelmis J. Fetal tobacco syndrome and perinatal outcome. Fetal Diagn Ther. 2002;17:367-71. PMID:12393968 DOI: $10.1159 / 000065387$

Iranloye BO, Bolarinwa AF. Effect of nicotine administration on weight and histology of some vital visceral organs in female albino rats. Niger J Physiol Sci. 2009;24:7-12. PMID:19826458 DOI: $10.4314 /$ njps.v24i1.46374

Jacobsen LK, Picciotto MR, Heath CJ, Frost SJ, Tsou KA, Dwan RA, Jackowski MP, Constable RT, Mencl WE. Prenatal and adolescent exposure to tobacco smoke modulates the development of white matter microstructure. ] Neurosci. 2007;27:13491-8. PMID: 18057207 DOI: 10.1523/JNEUROSCI.2402-07.2007

Jo YH, Talmage DA, Role LW. Nicotinic receptor-mediated effects on appetite and food intake. J Neurobiol. 2002;53:61832. PMID:12436425 DOI: 10.1002/neu.10147

Kleinman JC, Pierre MB Jr, Madans JH, Land GH, Schramm WF. The effects of maternal smoking on fetal and infant mortality. Am J Epidemiol. 1988;127:274-82. PMID: 3337083

Lambers DS, Clark KE. The maternal and fetal physiologic effects of nicotine. Semin Perinatol. 1996;20:115-26. PMID: 8857697 DOI:10.1016/S0146-0005(96)80079-6

Langgassner J. Rauchgewohnheiten der österreichischen Bevölkerung. Stat Nachr. 1999;5:319-26.

Narahara $\mathrm{H}$, Johnston JM. Smoking and preterm labor: effect of a cigarette smoke extract on the secretion of platelet-activating factor-acetylhydrolase by human decidual macrophages. Am J Obstet Gynecol. 1993;169:1321-6. PMID: 8238201 DOI: 10.1016/0002-9378(93)90300-8

NIH - National Institute of Health. Guide for the Care and Use of Laboratory Animals, No. 85-23. Washington: The National Academies Press; 1996.
Omotoso GO, Ibitolu JO, Femi-Akinlosotu OM, Akinola OB, Enaibe BU. Morphological and neurohistological changes in adolescent rats administered with nicotine during intrauterine life. Niger J Physiol Sci. 2013;28:147-51.

Oyeyipo IP, Raji Y, Emikpe BO, Bolarinwa AF. Effects of oral administration of nicotine on organ weight, serum testosterone level and testicular histology in adult male rats. Niger J Physiol Sci. 2010;25:81-6. PMID: 22314908

Oyeyipo IP, Raji Y, Emikpe BO, Bolarinwa AF. Effects of nicotine on sperm characteristics and fertility profile in adult male rats: a possible role of cessation. J Reprod Infertil. 2011;12:201-7. PMID: 23926503

Ramos EJ, Meguid MM, Zhang L, Miyata G, Fetissov SO, Chen $C$, Suzuki S, Laviano A. Nicotine infusion into rat ventromedial nuclei and effects on monoaminergic system. Neuroreport. 2004;15:2293-7.

Rosevear SR, Holt DW, Lee TD, Ford WC, Wardle PG, Hull MG. Smoking and decreased fertilization rates in vitro. Lancet. 1992;340:1195-6. DOI: 10.1016/01406736(92)92895-M

Thakur GA, Sengupta SM, Grizenko N, Schmitz N, Pagé V, Joober R. Maternal smoking during pregnancy and ADHD: a comprehensive clinical and neurocognitive characterization. Nicotine Tob Res. 2013;15:149-57. PMID:22529219 DOI: $10.1093 /$ ntr/nts102

Tuormaa TE. The adverse effects of tobacco smoking on reproduction and health: a review from the literature. Nutr Health. 1995;10:105-20. PMID: 7491164 DOI: $10.1177 / 026010609501000202$

Underwood P, Hester LL, Laffitte T Jr, Gregg KV. The relationship of smoking to the outcome of pregnancy. Am J Obstet Gynecol. 1965;91:270-6. DOI: 10.1016/0002-9378(65)90211-5

Walsh SW, Wolf RC, Meyer RK, Robinson JA. Estrogens in the uteroovarian, uterine, and peripheral plasma in pregnant rhesus monkeys. Biol Reprod. 1979;20:606-10. PMID: 110369 DOI: 10.1095/biolreprod20.3.606

Xue Y, Morris M, Ni L, Guthrie SK, Zubieta JK, Gonzalez $\mathrm{K}$, McConnell DS, Domino EF. Venous plasma nicotine correlates of hormonal effects of tobacco smoking. Pharmacol Biochem Behav. 2010;95:209-15. PMID: 20100507 DOI: $10.1016 / j . p b b .2010 .01 .007$

Zoli M, Picciotto MR. Nicotinic regulation of energy homeostasis. Nicotine Tob Res. 2012;14:1270-90. PMID: 22990212 DOI: $10.1093 /$ ntr/nts 159 